\title{
Research on Physical Education Teaching Based on the Stratified-teaching Mode
}

\author{
Ying Liu \\ College of Physical Education, Taishan University, Tai'an, Shandong 271000, China
}

Keywords: the stratified-teaching mode; physical education; application; research.

\begin{abstract}
The stratified-teaching mode is the product of the teaching reform, and it conforms to the educational idea of teaching students in accordance with their aptitude in the new curriculum. It is of great significance to apply the stratified-teaching mode into physical education, because it can satisfy the needs of different students for teaching to effectively promote their personality development. It breaks through the traditional bottleneck of teaching and makes the students form a lifelong physical education consciousness; in addition, it also helps to cultivate students' specialized ability of sports. This paper elaborated on the thought, significance and specific methods of stratified teaching in physical education as well as the implementation strategies of stratified physical teaching.
\end{abstract}

\section{Introduction}

China is a country having large population and relatively limited educational resources. There are generally many students in every class, but the number of PE teachers hardly matches with the number of students. Therefore, the main form of physical education is the classroom teaching which takes the class as the teaching unit. In this situation, the stratified teaching is a more effective strategy of teaching to help all students in the class to benefit from the physical education. The stratified PE teaching refers to that teachers carry out multi-level teaching according to the students' actual age, physical and mental characteristics, skill level of sports, sports foundation, physique and other physical characteristics; and they also make different teaching objectives and teaching contents, adopt different teaching methods and implement different evaluation systems for students at different levels, in order to improve the quality of PE teaching.

\section{The Theory of Stratified Teaching in Physical Education}

There generally are great differences in the physiological characteristics and physical qualities of the students of different ages. The teaching of other subjects requires high level of students' intelligence, while the physical education proposes high requirements to students' physical quality. It is difficult to understand the physical ability of students in the same grade from their appearance and it is necessary to carry out the evaluation of the students through the practice of exercise. Every student has his/her unique personality, and different students also have differences in all aspects, such as their interest, hobbies and physique. These differences are also the basis of the study of PE teaching strategies. If these differences between students are not taken into account, it is difficult to achieve the efficient classroom teaching in physical education.

In the new curriculum standards, teaching should be centered on the development of students. The students here include both the students of all ages and the ones at the same age in the same class. The classroom teaching of physical education is the main channel for students to receive physical exercise, and it is mainly implemented by taking the class as a unit. Therefore, PE teachers must carry out the teaching practice around the stratified teaching, so as to make the students of every age group get the corresponding sports education. 


\section{The Advantages of the Application of Stratified Teaching in Physical Education}

\subsection{Realizing Targeted Teaching Methods}

Under the background of exam-oriented education, teachers and school leaders lay stress on students' intellectual disciplines, and not give much attention to the physical education which does not take up scores in the exam. Therefore, the position of physical education is low in the school, and the teachers of other disciplines can take up the time of physical education at will to carry out their teaching activities. Especially in remote areas, physical education is hardly carried out and some schools even cancel the related courses, due to the limited level of teachers, neglect of the importance of physical education and the lack of sports equipment. This has a serious effect on the students' exercise performance and their physical constitution. In the same school, students generally come from different places and the physical education they have received is also different, which leads to a great difference in athletic ability and sports knowledge between students of the same age group. In this sense, targeted teaching according to the characteristics of the students is an effective way to improve the efficiency of physical education.

\subsection{Promoting the Development of Students' Interest and Personality}

Interest is the psychological tendency of people to engage in social activities. It can increase the motivation of people and improve the effect of activities. Therefore, teachers should focus on stimulating students' interest in learning in all kinds of activities of physical education to develop their personalities. This is also the requirement of educational reform and the development of the times. Students of different ages prefer different sports activities. For example, pupils generally have strong curiosity and they are interested in all kinds of activities. The hobby of middle school students is more concentrated. For example, they may only like the ball activities or running. The hobby of college students is more stable and they may only prefer one kind of sport. Students of the same age also have differences in sports hobbies, even if they have some common characteristics in physical and psychological development. For example, boys like sports with large amount of exercise, such as sports, running and jumping; girls generally prefer activities with small amount of exercise like gymnastics. Students with different disposition also show different preference for different sports items. For example, introverted students prefer activities with small range of movements while extroverts prefer the ones with great range of movements. These differences lead to different demands of students for sports items, which also puts forward new requirements for physical education. Therefore, carrying out stratified teaching on students can promote students' interest and personality development.

\subsection{Breaking the Traditional Teaching Mode}

The traditional teaching is dominated by the knowledge-feeding mode which takes teachers as the main body in teaching. Although the venue and teaching mode of physical education are relatively special, teachers are still the main body in teaching philosophy, which has a certain impact on students' learning and development. Under the background of promoting the new curricula, the idea of taking students as the main body in teaching has become the mainstream trend of the teaching thought. Stratified teaching is a teaching mode that takes students as the main body of teaching. Its main characteristic is to design teaching objectives, adjust teaching contents, choose teaching means and optimize teaching evaluation according to students' actual conditions, capabilities and sports basis, so as to promote the balanced development of all students. The stratified teaching can break the traditional teaching mode and cover its shortage, so that students of different levels can get the corresponding development.

\subsection{Promoting Students to form the Consciousness of Lifelong Physical Education}

The idea of lifelong physical education was first put forward in Japan for the implementation of national sports, and it has been carried out in the education of primary and secondary schools throughout this country. The elective system implemented by some schools in our country is similar to that of Japan, both of which enable students to choose sports items according to their interests and abilities. The stratified-teaching mode is based on this. Its implementation can improve students' autonomy, creativity and independence. Moreover, this way of teaching gives student's greater 
choice. They can choose the textbook, teaching method and teaching evaluation according to their interests and needs, thus forming consciousness and behavior of lifelong sports.

\subsection{Improving Teachers' Quality}

The stratified PE teaching raises high requirements to the PE teachers. In addition to solid physical knowledge and professional skills, teachers are expected to have knowledge reserves in psychology and sociology to analyze the differences between students in different ages and their physical and mental differences. At the same time, teachers must have diversified teaching means to apply different teaching methods on different students, so as to improve the overall physical quality of students. Therefore, in the stratified physical education, a qualified PE teacher needs not only rich professional knowledge but also knowledge of sociology and pedagogy; in addition, the teacher is supposed to accumulate teaching experience and teaching methods constantly in practice and have some innovative ability to adapt to the needs of stratified teaching in physical education.

\section{The Concrete Operation Methods of Stratified Teaching in PE Teaching}

\subsection{To Stratify Based on Students Sports Foundation}

In stratified teaching, to stratify students is the main part of the whole teaching. Teachers need to evaluate and understand students' physical quality, athletic ability, personality traits and foundation of sports knowledge, and then apply stratified teaching on students in different levels. Students can be stratified into three levels according to their comprehensive performance, namely I, II and III. These three levels correspond to three kinds of students, respectively are: outstanding students who have solid sports foundation and perfect physical quality; medium students with basic knowledge of sports and good comprehensive quality; students with learning difficulties who have weak basic knowledge of physical education and poor physical quality. Generally speaking, the proportion of medium students account for about $60 \%$ in a class, and the outstanding students and students with learning difficulties respectively account for about $20 \%{ }^{[4]}$. The result of stratification is not unalterable, and teachers need to adjust the stratification ratio appropriately according to the progress of students. For example, after long-term exercise and study, the comprehensive quality and sports knowledge of some medium students have been greatly improved, and then they can be stratified as the outstanding students if they meet relevant requirements; and vice versa. This kind of stratification can not only help to teach students in accordance with their aptitude, but also can mobilize their enthusiasm through the rise and fall of the hierarchy.

\subsection{To Stratify According to Students' Gender}

Due to the limited teacher resources, lack of sports venues and other factors, boys and girls attend the same PE class in some schools. However, it is not scientific, because there are certain differences in the athletic ability, physical quality and interests between them. The stratification of male and female students is the most basic part in stratified teaching. In this kind of teaching, teachers can design the teaching content separately according to the characteristics of male and female students. The teaching contents of male students can contain some sports items with large amount of exercise and higher physical quality requirements, while teaching contents for girls should be dominated by sports items with low physical quality requirements. In addition, teachers should design corresponding teaching objectives and assessment targets according different contents. Therefore, teachers must analyze the physical and mental basis, ability and endurance of boys and girls in the class before teaching, and then design textbooks, teaching contents and teaching objectives according to the differences between them.

\section{The Specific Strategies of Stratified Teaching in Physical Education}

\subsection{Rationalization of Stratified Targets}

The teaching objective is the guidance for teachers in the teaching, and thus it is related to the efficiency of teaching. In the objective design of PE teaching, teachers should give full consideration to the different levels of students' physical quality, skills, hobbies and other aspects to set different 
teaching objectives, so that students at every level can have a clear learning goal and achieve goal-oriented learning and practice. In this way, students at all levels are able to take exercises adapted to their abilities and get promoted. Specifically, for outstanding students, it is necessary to set high goals and urge them to study and exercise harder; the standards of outstanding student can be proposed to medium students, so as to promote them to realize the promotion through continuous efforts; for students with poor physical ability and quality, teachers should encourage them to meet the standard of qualification through continuous efforts. In addition, teachers should use teaching methods and means flexibly. The objective of stratified teaching can be put into practice by flexible use of teaching methods in practice.

\subsection{Selection of Different Teaching Modes According to the Difference of Different Levels}

In stratified PE teaching, teachers should not only help students master the corresponding sports skills and basic knowledge according to the standards of physical education, but also choose different teaching modes according to the differences of students at different levels. Most of the students with learning difficulties are characterized by poor basic knowledge of sports and sports skills, and they need the demonstration from teachers. Therefore, a series of teaching methods, such as creating teaching situation, demonstration and explanation, observation and imitation of students and self-consolidating, can be adopted to help student learn and practice. For the medium students, they have mastered basic sports knowledge and skills. When setting up situations, teachers can adopt the way of adding questions, students doing self-exploration, teachers correcting mistakes and students consolidating exercises in teaching. More space for self-study can be given to outstanding students. After providing the appointed problem, the students can explore independently and then discuss and practice in groups. The teacher gives directions according to the students' performance, and then they practice again and finally summarize by themselves.

\section{Conclusion}

To sum up, the stratified teaching of physical education fully follows the teaching idea centered on student development. It is a very important teaching method in current physical education in China. The stratified PE teaching is not a simple group-style teaching, but a reasonable stratification based on the students' ability and physical quality. Teachers should carefully set up the curriculum according to the specific situation of students, which can promote the balanced development of all the students. Therefore, the PE teacher must conduct thorough research on the stratified teaching, rather than only staying in the theory. They have to carry out a lot of teaching practice and make continuous reflection and improvement to make the stratified teaching better serve the teaching of physical education.

\section{References}

[1]. Zhang Qiang, Zhang Yuchen. Necessity of Hierarchical and Classified Teaching of Physical Education and Implementation Strategies [J]. Journal of Physical Education, 2014 (4): 98-100.

[2]. Guo Yongbao. On the Stratified Teaching of PE in Senior High Schools [J]. New Course $<$ Xin Ke Cheng>, 2012 (2): 148-148.

[3]. Yang Zhijian. The Study of Stratified-education Practice of Physical Education in Senior High Schools [J]. Teachers, 2012 (24): 50-50.

[4]. Gao Dexi. The Use of Stratified Education in Teaching [J]. Primary School Science, 2014 (2): 38-38. 